\title{
Glikozamin'in Mono ve di (2-bromoetil) amin Türevlerinin Sentezi ve Yapı Aydınlatması Üzerinde Çalışmalar ${ }^{1 *}$
}

Studies On the Synthesis and Sturucture Elucidation of mono and di (2-bromoethyl) amino Derivatives of Glucosamine ${ }^{1 *}$

Ningur NOYANALPAN** Hakverdi DEMIR***

Bazı halojenli poliollerin ve şekerlerin antineoplastik etki gösterdikleri bilinmektedir. ${ }^{1}$, et ref 1 loc cit. Literatür araştırmaları çeşitli şekerlerin hardal gazı yapısı içeren türevlerinin hazırlandığını ama bu arada amin fonksiyonu içeren moleküllerin hardal gazı türevlerinin hazırlanmadığını göstermiştirı. Bunun üzerine antineoplastik etkiyi elde etmek amacı ile laboratuvarımızda, amin fonksiyonu içeren şekerlerden glikozaminden başlayarak mono ve di türevleri şeklinde (2-bromoetil) amino yapıları elde edilmiştir. Bu yapılar temel olarak antineoplastik etki gösteren Degranol ve buna bağlı bileşiklere benzemektedir, aralarındaki en önemli ayrıcalık sentezi yapılan bu bileşiklerin amino fonksiyonu içermesidir.

\section{MATERYAL ve YÖNTEM}

Çalışmamızda başlangıç bileşiği olarak Glikozamin hidroklorür (Merck) kullanılmıstır. Sentez bileşiklerinin kristalizasyonu eterpetrol eteri karışımından ve buz dolabında 24 saat bekletilerek yapilmıștır.

Kullanılan çözücüler arıdır (MERGK) ve bütün çalışma boyunca standard cam sentez takımları kullanılmıştır.

Redaksiyona verildiği tarih: 28 Aralık 1977

* Eczacı Hakverdi DEMIR'in “Antitümör etkili ozların yapı değişimleri ile yeni türevlerin sentezi üzerinde araştırmalar" adlı doktora tezinden alınmıştır.

** Farmasötik Kimya Kürsüsü, Eczacılık Fakültesi, Ankara Úniversitesi

*** Ordu Ilaç Fabrikası, Ankara 
$\mathrm{Bu}$ çalı̧̧mada kromatografik yöntemler (ince tabaka kromatografisi, sütun kromatografisi), Ultraviyole spektrotofotometresi (Pye Unicam Sp 1700), Infrared spektrofotometresi (Pye Unicam Sp 1100), NMR Spektrometri (Perkin Elmer R-32, $90 \mathrm{MHz}$ ), ergime noktasi saptama aygıtı (Büchi) kullanılmıştır.

Ergime noktaları düzeltilmeden verilmiştir. IR spektrumları potasyum bromür pelleti ile alınmıştır.

\section{BULGULAR}

Her bileşiğin yanında bundan önceki yayınla birlikte verilmiş bulunan kod numarası bulunmaktadır.

1 (2-bromoetil) amino-2-asetamido-3.4.6-trihidroksi glikopiranoz: (XVII)

$\mathrm{Bu}$ bileşik daha önce sentezi verilmiş bulunan ${ }^{1}, 1$-kloro-2-asetamido-3,4,6-triasetil glikopiranoz ve etilenimin kullanılarak yapıldı. Hazırlanan bileşik kromatografik olarak incelenip arılığı saptandı. En: $210^{\circ} \mathrm{C}$ (dekompozisyonla) Halojen arama reaksiyonu ile halojenin varlığı saptandı, brom olduğu kanıtlandı. IR spektrumunda; $3460 \mathrm{~cm}^{-}-, 1590 \mathrm{~cm}^{-1}, 1440 \mathrm{~cm}^{-1}, 1070 \mathrm{~cm}^{-1}$ bandları saptand.

Tüm incelemeler sonunda bileşiğin 1(2-bromoetil) amino-2asetamido-3,4,6.-trihidroksi glikopiranoz olduğu saptandı.

1-etilimino-2-asetamido-6-tosil-3.4-dihidroksi-glikopiranoz: (XVIII)

$\mathrm{Bu}$ çalışmada daha önce hazırlanan 1-kloro-2-asetamido-2dezoksi-3.4.6-triasetil glikopiranoz ile etilenimin ve p-toluensülfonil klorür kullanıldı. Elde edilen ürünün kromatografik düzeyde arılığı saptandı. Bu reaksiyonda daha önce yararlanılmış bulunan spesifik tosilasyon ${ }^{1}$ kullanıldı.

Yapılan incelemeler sonunda bileşiğin 1-etilimino-2-asetamido -6-tosil-3.4-dihidroksi glikopiranoz olduğu saptandı.

1-etilimino-2-asetamido-6-bromo-3.4-dihidroksi glikopiranoz: (XIX)

XVIII nolu bileşikten hareket edildi. Elde olunan bileşiğin ince tabaka kromatografisi ile arılığı saptandı. Halojen aranarak, varlığı ve brom olduğu gösterildi. 


\section{6-di (2-bromoetil) amino-2-amino glikopiranoz: $(X X)$}

Başlangiç bileşiği olarak XIX nolu bileşik kullanıldı. Tüm reaksiyonların sonunda elde edilen bileşiğin kromatografik düzeyde arı olduğu saptandı. Kristalizasyonla temizlenen bileşik daha ileri incelemelere sokuldu.

En: $239^{\circ} \mathrm{C}$ (dekompozisyonla), halojen aranmasi reaksiyonu olumlu sonuç verdi. IR spektrumunda $3460 \mathrm{~cm}^{-1}, 1590 \mathrm{~cm}^{-1}, 1440$ $\mathrm{cm}^{-1}, 1070 \mathrm{~cm}^{-1}, 655 \mathrm{~cm}^{-1}$ bandları saptand.

Yukarıda anlatılan tüm incelemeler sonucu bileşiğin 1.6-di (2-bromoetil) amino-2-amino glikopiranoz olduğu saptandi.

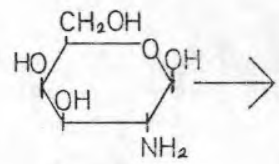

Glikozamin<smiles>CC(=O)N[C@H](O[C@H](C)CO)[C@H](O)CO</smiles>

(1)2-Asetamido2-Dezoksi$\alpha$-D-glikopiranoz

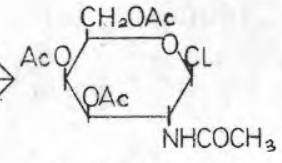

(VIII) 1-kloro-2-Aset Amido 3,4,6-Tri asetil glikopiranoz
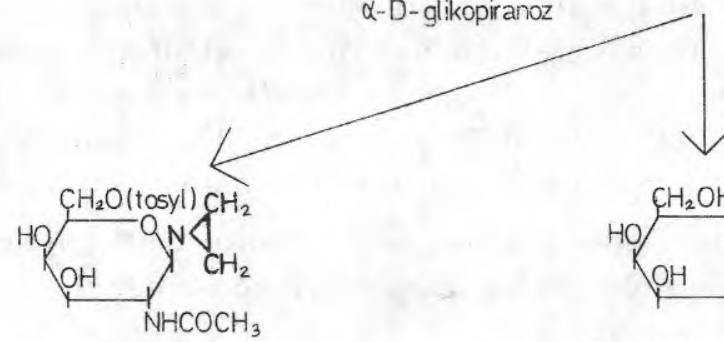

(XVIII)-Etilımno 2-Asetamido

6-tosil-3,4-dihidroksi qlikopranoz

$\downarrow$<smiles>CC(=O)N[C@@H]1C[C@@H](O)[C@@H](Br)O[C@H]1C1CC1</smiles>

(XIX) 1-Etilimino-2-Asetamido

3,4-dihidroksi-6-Bromo glikopiranoz

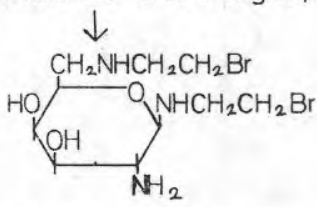

(XX) 4,6-di(2-bromoetil)-

2-Amino glikopiranoz

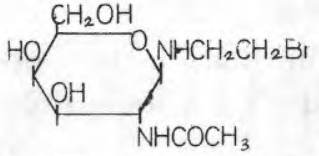

(XVII)-1(2-Bromoetil)amino-2-Asetami) in 3,4,6-Trihidroksi glikopiranoz 


\section{DENEYSEL KISIM}

\section{2-kloroetil amin hidroklorür: (XIV)}

$61 \mathrm{~g}$ (1 Mol) etanol amin tartıldı. Buz banyosu üzerine kanularak 30 dakika soğutuldu. $129.8 \mathrm{~g}(1.1 \mathrm{Mol})$ tiyonil klorür tartıldı. buz banyosu içindeki etanol amin üzerine 2.5 saat süre içinde damla damla katıldı. Kahverengi bir çökelek oluştu. Bu çökelek 24 saat açık havada tutuldu. 24 saat sonra bu kahverengi çökelek suda çözüldü, aseton katılarak kristallenmesi temin edildi. Kristaller vakumda süzülerek ayrıldı ve kurutuldu.

Elde olunan bileşikte şu çalışmalar yapıldı:

En: $143^{\circ} \mathrm{C}$. Halojen aranması olumlu sonuç verdi. Kromatografik tek leke olduğu saptand, IR spektrumu çizildi.

\section{$\beta$ - kloroetil amin: $(X V)$}

$115 \mathrm{~g}$ (1 Mol) 2-kloroetil amin hidroklorür tartıldı, balon içindeki bileşik bir buz banyosu üzerine konuldu. Úzerine $150 \mathrm{ml} 8 \mathrm{~N}$ $\mathrm{NaOH}$ çözeltisinden damla damla katıldı. Tüm $\mathrm{NaOH}$ katıldıktan sonra balonun 1 sisı $50^{\circ} \mathrm{C}$ a getirilip 2 saat bekletildi. Daha sonra $70-90^{\circ} \mathrm{C}$ arasında distile edildi. Distilatın fiziksel özellikleri ve klor taşıyıp taşımadığı araştırıldı, klor içerdiği ve serbest baz olduğu anlaşıldıktan sonra hemen etilenimin hazırlanılışına geçildi.

\section{Etilenimin (Aziridin) : (XVI)}

$100 \mathrm{ml}$ kloroetilamin bir balona alındı. $50 \mathrm{~g} \mathrm{NaOH}$ tartıld 1 ve katı haldeki $\mathrm{NaOH}$ birinci balona yavaş yavaş katıldı. $70^{\circ} \mathrm{C}$ de geçen distillat toplandı $(17 \mathrm{ml})$ içerisine $3-4 \mathrm{NaOH}$ pelleti katılarak ağzı kapatıldı ve buz dolabında bekletilmeye konuldu.

\section{1(2-bromoetil) amino-2-asetamido-3.4.6-trihidroksi glikopiranoz: (XVII)}

$5 \mathrm{~g}$ kloroasetamido triasetil glikozamin tartıldı, üzerine $50 \mathrm{ml}$ susuz benzen katıldı, daha sonra $5 \mathrm{ml}$ aziridin katıldı, 96 saat çalkalayarak beletildi. Bu süre sonunda balon buz banyosu üzerine yerleştirildi, \% 48 lik $\mathrm{HBr}$ asit katılarak kristallendirildi. Kristaller $\mathrm{HBr}$ ile yıkanarak alındı ve kurutuldu. 
En: $210^{\circ} \mathrm{C}$ (dekompozisyonla), halojen aranması olumlu sonuç verdi.

1-etilimino-2-asetamido-6-tosil-3.4-dihidroksi glikopiranoz: (XVIII)

5 g Etilimino-2-asetamido-3.4.6-trihidroksi glikopiranoz tartıldı, bir balona alındı, üzerine $5 \mathrm{ml}$ piridin, $4 \mathrm{~g}$ p-toluensülfonilklorür katıldı. 24 saat buzdolabinda bekletildi. 24 saat sonra kuruluğa kadar uçuruldu. Kalıntıdan hareketle yapılan kromatografik çalışmalar başlangıç bileşiğinden ayrı ve tek leke veren bir bileşiğin elde edildiğini gösterdi. Bu bileşiğin daha fazla arılaştırılmasina çalışılmadan hemen bir sonraki reaksiyona geçildi.

1-etilimino-2-asetamido-3.4-dihidroksi-6-bromo glikopiranoz: (XIX)

Bir önceki reaksiyonda elde edilen (XVIII Nolu bileşik) bileşikten $5 \mathrm{~g}$ tartıldı, $20 \mathrm{ml}$ aseton içinde çözüldü. Bu çözelti üzerine nicel yönden denk oranda $\mathrm{NaBr}$ katıldı. Geri çeviren soğutucu altında $70^{\circ} \mathrm{C}$ de $36^{\circ}$ saat süre ile isitıldı. 36 saat sonra $0^{\circ} \mathrm{C}$ ye getirildi ve süzüldü. Süzüntü kuruluğa kadar uçuruldu, $20 \mathrm{ml}$ aseton katıldı, kristalizasyona birakıldı. Kristaller eter ile yıkanarak alındı, kurutuldu.

1.6-di (2-bromoetil) amino-2-amino glikopiranoz: $(X X)$

$5 \mathrm{~g}$ 1-etilimino-2-asetamido-3.4-dihidroksi-6-bromo glikopiranoz tartıldı, önce $20 \mathrm{ml}$ benzen daha sonra $5 \mathrm{ml}$ aziridin katıldı. 96 saat oda isısında bekletildi. Bu süre sonunda: \% 48 lik $\mathrm{HBr}$ çözeltisinden katılarak kristallendirildi. Kristaller $\mathrm{HBr}$ in fazlasıyla yıkanarak alındi, kurutuldu.

En: $239 \mathrm{C}$ (dekompozisyonla), halojen aranması reaksiyonu olumlu sonuç verdi, kromatografik leke sayısı bir olarak bulundu, IR spektrometri ile elde edilen yapı kesinlik kazand.

\section{SONUÇ ve TARTIŞMA}

Giriş kısmında da belirtildiği gibi bu çalışmada Degranol benzeri 2-bromoetil aminli şeker türevleri hazırland. Ancak bu kez sentezlenen türevler amin grupları içermektedir. Amin grubu içeren türev olarak glikozamin ele alınmıştır. Çalışmanın sonunda elde edilen iki türev; hem bir adet 2-etil amino fonksiyonu taşıyan hem de iki adet 2-etil amino fonksiyonu taşıyanlar yeni türevlerdir. 
$\mathrm{Bu}$ bileşikler taşıdıkları alkilleyici gruplar nedeni ile zamanımızda kullanılmakta olan antineoplastik bileşiklere benzemektediri. Türedikleri ana yapı olarak da organizmada kolay metabolize edilen bileşiklerdir. Glikozaminin bu yapılar içinde yer alışı ile etkinin daha iyi olacağı düşünülmüştür.

\section{ÖZET}

Bu çalışmada glikozaminden başlayarak, DEGRANOL benzeri bileşikler sentez edildi. Sentezi yapılan bileşikler: 1(2-bromoetil) amino ve 1.6 -di (2-bromoetil) amino glikozamin türevleridir. Ayrıca bu türevlerin sentezi için gerekli olan başlangıç bileşiği niteliğindeki bazıları ile sonuç bileşiklerine varabilmek için gerekli olan ara ürünleri niteliğindeki glikoz türevleri de hazırlanmıştır.

Hazırlanan bu türevlerin yapı aydınlatmaları çalışılmıştır.

$\mathrm{Bu}$ türevlerin biyolojik etkileri daha sonra yayınlanacaktır.

\section{SUMMARY}

In this research, DEGRANOL like derivatives have been synthesized starting from glucosamine. These compounds are: 1(2-bromoethyl) amine and 1.6-di (2-bromoethyl) amino derivatives of glucosamine. Also some other starting compounds and intermediary ones which were needed for obtaining the above mentioned target derivatives have been synthesized.

Structure elucidation of all compounds have been worked out.

Biological effects of these derivatives will be published later.

\section{LITERATÜR}

1. Noyanalpan, N., Demir, H., Ankara Ecz. Fak. Mec. 7, 77 (1977)

2. Sellei, G., L.N., Chemotherapy of Neoplastic Diseases, Academia Kiedo, Budapest (1970). 


\section{BİLIMSEL HABERLER}

\section{Tezler :}

1. Ecz. Bilge Iren

"D-Homosteroid yapısının sentezi ve yapı aydınlatması üzerinde çalışmalar". Doktora Tezi (1977)

\section{Seminer ve Korferanslar:}

1. Hollanda Leiden Úniversitesi Farmasötik Teknoloji ve Biyofarmasötik Kürsüsü Profesörü Prof. Dr. Polderman 27-28 Aralık 1977 tarihlerinde fakültemizde konferanslar vermiştir.

2. Prof. Dr. Enver Izgü ve Dr. Pharm. Nilüfer Tarımcı 4-9 Eylül 1977 tarihlerinde Lahey'de yapılan 37. Uluslararası Eczacılık Kongresine katıldılar.

3. Dr. Ilbeyi Ağabeyoğlu ve Dr. Kandemir Canefe 7-8 Ekim 1977 tarihlerinde Trab zon'da iki konferans verdiler. 


\section{Fakülte Profesörler Kurulunun 10.3.1970 tarih ve 358 sayılı Kararı ile Fakülte Mecmuasında yayınlanacak yazılar için tesbit edilen esaslar}

1) Dergide, başka bir mecmuada aynı isimle ve aynı tarzda neşredilmemiş orijinal çalışmalar yayınlanır.

2) Yazılar Komisyona verildiği tarih sırasıyla yayınlanır.

3) Metin 15 daktilo sayfasını geçmemek üzere Türkçe veya yabancı dilde yazılabilir. Metin başlığı ve özeti Türkçe ve yabancı dilde yazılacaktır.

Yabancı dilde yazılmış başlık, metin ve özetlerin dil kurallarına uygun olmasının temini, yazara aittir.

4) Yazılar, kâğıdın bir yüzüne, daktilo ile ve normal aralıkla yazılmalı, italik yażlacak kelimelerin altı çizilmeli, klişesi yapılacak grafik, şema, formül gibi şekiller, çini mürekkep ile, aydinger kâğıdına çizilmeli; fotoğraflar parlak kâğıda ve kontraslı olarak çekilmelidir. Şekillerin her biri ayrı kâğıtlarda olmalı ve kâğıdın üzerinde yazarın adı, kaçıncı şekil olduğu, resim altı yazılması istenen ibare kaydedilmelidir.

5) Yazı plânı aşağıdaki şekilde olmalıdır: Konunun takdimi, bulgular, denel kısım, münakaşa, Türkçe özet, yabancı dilde özet, literatür.

Konunun takdimi 2 daktilo sahifesini geçmemeli; materyal, metot ve yapılan ameliyeler "denel kısım" da yer almalı, "münakaşa" kısmı, gerekli ise konmalıdır.

Literatür, metinde parentez içindeki numaralarla belirtilmesi ve metin sonunda bu numaralara uygun olarak sıralanmalıdır. Sırasıyla yazarın soyadı, adının ilk harfi, mecmuanın milletlerarası kullanılan kısaltılmış ismi, cilt numarası (italik), sayfa ve parentez içinde tarih yazılmalıdır.

6) Tashihler yazar tarafından yapılacaktır.

7) Yazara 50 ayrı baskı verilir. 